\title{
Developmental Outcome of Very-Low-Birth-Weight Infants without Major Brain Injuries Based on Data from the Korean Neonatal Network: A Nationwide Cohort Study
}

Jong Ho Cha, $\mathrm{MD}^{1}$, Nayeon Choi, $\mathrm{MD}^{2}$, Yun Jin Kim, $\mathrm{PhD}^{2}$, Hyun Ju Lee, $\mathrm{MD}, \mathrm{PhD}^{1}$, Chang Ryul Kim, $\mathrm{MD}, \mathrm{PhD}^{3}$, and Hyun-Kyung Park, MD, $\mathrm{PhD}^{1}$

${ }^{1}$ Department of Pediatrics, Hanyang University College of Medicine, Seoul, Korea

${ }^{2}$ Biostatistical Consulting and Research Lab, Medical Research Collaborating Center, Hanyang University, Seoul, Korea

${ }^{3}$ Department of Pediatrics, Hanyang University Guri Hospital, Guri, Korea

\section{ABSTRACT}

Purpose: As preterm infants have shown advances in survival rate, many very-lowbirth-weight (VLBW) infants have shown developmental delay even without a major brain injury. Thus, the incidence of and risk factors associated with poor neurodevelopmental outcome should be evaluated.

Methods: A multicenter nationwide prospective longitudinal cohort study of VLBW infants born in South Korea between 2013 and 2015 was conducted. Poor neurodevelopmental outcome was diagnosed if the Bayley Scales of Infant and Toddler Development (BSID)-III composite score was $\leq 85$ (cognition, language, motor). We analyzed the associations of baseline neonatal characteristics, environmental characteristics and neonatal morbidities with poor neurodevelopmental outcome.

Results: The study included 285 infants, of whom 34 (11.9\%) exhibited cognition delay; 59 (20.7\%), showed language delay and $32(11.2 \%)$ showed motor delay. The mean gestational age and birth weight were 29 weeks and 1,130 g, respectively. Moderate and severe bronchopulmonary dysplasia $(P=0.056)$ and intraventricular hemorrhage grade I $(P=0.079)$ were marginally associated with cognition delay. Higher paternal educational level $(P<0.05)$ was significantly associated with the language outcome. Birth weight $(P<0.05)$ and head circumference at discharge $(P<0.05)$ were the major predictors of motor delay.

Conclusion: The population-based nationwide cohort study shows that approximately $20 \%$ of VLBW infants without major brain injury have developmental delay. Several factors that are not directly associated with major brain injury were significantly associated with poor neurodevelopmental outcome.

Key Words: Premature; Bayley-III; Infant, very low birth weight; Cohort studies; Longitudinal studies
Received: 8 April 2020

Revised: 8 June 2020

Accepted: 9 June 2020

Correspondence to: Hyun-Kyung Park, $\mathrm{MD}, \mathrm{PhD}$

Department of Pediatrics, Hanyang University Seoul Hospital, 222-1 Wang simni-ro, Seongdong-gu, Seoul 04763, Korea

Tel: +82-2-2290-8397

Fax: +82-2-2297-2380

E-mail: neopark@hanyang.ac.kr

Copyright(c)

By Korean Society of Neonatology.

All right reserved.

This is an Open-Access article distributed under the terms of the Creative Commons Attribution Non-Commercial License (http:// creativecommons.org/licenses/by-nc/4.0), which permits unrestricted non-commercial use, distribution, and reproduction in any medium, provided the original work is properly cited. 


\section{INTRODUCTION}

As there has been a marked improvement in the survival rates of preterm infants, their long-term developmental outcomes have become a subject of great concern. Although the survival rates of preterm infants has shown remarkable advancement, from $65.8 \%$ in the 1990 s to $89.7 \%$ in $2009^{1)}, 30 \%$ of preterm infants showed developmental delay in South Korea ${ }^{2}$. In fact, $75 \%$ of preterm infants are known to have developmental disabilities around the age of 5 years ${ }^{3)}$.

Several researches have been conducted to identify the risk factors for developmental delay in preterm infants. In particular, low gestational age, especially birth at $<24$ weeks of gestation, has been known to have a significant effect on developmental delay. Also, it is well known that factors including low birth weight, low Apgar score, prolonged ventilator use, hypoglycemia, absent antenatal steroid, bronchopulmonary dysplasia (BPD), and retinopathy of prematurity (ROP) are significant factors of poor neurodevelopmental outcome $\mathrm{e}^{4-7)}$.

Although brain magnetic resonance imaging (MRI) has been a widely accepted tool for the diagnosis of adverse neurode velopmental outcome, there have been discrepancies between the MRI findings and clinical outcome. Woodward et al. ${ }^{8)}$ showed that $15 \%$ of preterm infants with normal findings in brain MRI showed severe neurodevelopmental delay. Also, in a subsequent study $^{9}$, , preterm infants with mild brain MRI abnormality were approximately three times likely to have developmental delay at the ages of 4 to 6 years. These previous studies imply the existence of relevant factors other than major brain injury that could impact on developmental delay. However, in our knowledge, nationwide cohort studies that identified the risk factors for very-low-birthweight (VLBW) without major brain injury have been lacking.

The Bayley Scales of Infant and Toddler Development (BSID) test was revised and reconstructed into the third edition, which includes a separation of the mental developmental index into the cognitive and receptive and expressive language scales. Compared with the second edition, BSID-III provides advantage on the detailed evaluation of infants' developmental status as it is newly revised in 20 years to reflect the latest trends in developmental research ${ }^{10)}$. From our knowledge, the neurodevelopmental outcome of VLBW infants using the BSID-III test has not been widely studied in South Korea.

The present study aimed to describe the incidence of the de velopmental outcome of VLBW infants without major brain in- jury. Also, using the nationwide database from the Korean Neonatal Network(KNN), the study aimed to establish the risk factors for the poor neurodevelopmental outcome.

\section{MATERIALS AND METHODS}

\section{Study population}

The study is a prospective longitudinal cohort study with VLBW infants enrolled in the KNN. The KNN is an ongoing webbased nationwide registry database participated by 69 hospitals across South Korea ${ }^{11,12)}$. The registry includes approximately $70 \%$ of all VLBW infants born in South Korea. The registry database collects not only prenatal and postnatal data but also post-discharge data, including the results of the BSID test at corrected ages of 18 to 24 months. Written informed consent was obtained from the parents upon enrollment at each participating hospital. From the KNN registry, we included VLBW infants who were born between January 2013 and December 2015 with birth weights of $<1,500 \mathrm{~g}$ and underwent the BSID-III test at corrected ages of 18 to 24 months. The exclusion criteria were VLBW in fants with major congenital malformations including genetic anomalies and malformation of a major organ system. VLBW infants with seizure and periventricular leukomalacia (PVL) and intraventricular hemorrhage (IVH) grade II or higher were also excluded.

\section{Neonatal variables}

The collected prenatal data included multiple gestations, normal pregnancy and in vitro fertilization and embryo transfer, gestational diabetes mellitus, pregnancy-induced hypertension, clinical and histological chorioamnionitis, administration and completion of antenatal corticosteroid therapy, delivery method, maternal age, and maternal and paternal educational level. The educational level of the parents was classified into two groups according to whether they have graduated from college or not.

The analyzed perinatal data included gestational age, sex, and body measurements (weight and head circumference) at birth. The variables in the delivery room included 1- and 5-minute Apgar scores and implementation of neonatal resuscitation. Respiratory and cardiac statuses in the neonatal intensive care unit (NICU) were investigated as the presence of respiratory distress syndrome and patent ductus arteriosus. Also, the use of steroid therapy and diagnosis and grade of BPD were considered. 
The diagnosis and severity of BPD were defined by the need for supplemental oxygen support at 28 days of postnatal age and 36 weeks of corrected age ${ }^{13)}$. ROP was defined using the international committee criteria, and necrotizing enterocolitis (NEC) was defined as higher than stage II according to modified Bell's criteria $^{14)}$. IVH grade I was defined according to the classification of Papile et al. ${ }^{15)}$ Culture-proven sepsis, duration (days) of total parenteral nutrition (TPN), and automated auditory brainstem response result were also included in the neonatal variables. The body measurements at the time of NICU discharge were considered.

\section{Neurodevelopmental assessment}

In the registry, the BSID-II or BSID-III test was performed for VLBW infants depending on the routine procedure in the followup center. In the study, we included infants who underwent the BSID-III test at corrected ages of 18 to 24 months. Cerebral palsy (CP) was defined as a permanent disorder of movement and posture that causes limitations of physical activity that are attributed to nonprogressive disturbances in the fetal or infant brain and graded according to the Gross Motor Function Classification System of Palisano and associates for children aged $\leq 2$ years $^{16)}$. Developmental delay was defined as a composite score of $\leq 85$ ( $\leq 1$ standard deviation $[S D]$ ) in each category ${ }^{17)}$. Moderate delay was defined as a composite score of $\leq 70$ ( $\leq 2 \mathrm{SD})$, and severe delay was defined as a composite score of $\leq 55$ ( $\leq 3 \mathrm{SD})$.

\section{Statistical analysis}

The baseline demographic, anthropometric, and clinical characteristics of the study population were described using either the median (interquartile range [IQR]) or numbers of cases (percentage). For categorical variables, the chi-square and Fisher exact tests were used to compare the associations of variables between the normal development and developmental delay groups. The Mann-Whitney $U$ and Wilcoxon rank-sum tests were used to compare continuous variables. To identify the quantitative relationships between variables, analysis was performed in two steps: a univariate analysis and then a multivariate analysis. The univariate logistic regression analysis was employed to identify the variables that showed an apparent association with neurodevelopmental impairment. Then, the multivariate logistic re gression analysis was performed to identify the strong predictors for the adverse neurodevelopmental outcomes. In the multivariate analysis, gestational age and birth weight were included in the analysis assessing outcome prediction. All analyses were performed using SAS version 9.4 (SAS Institute Inc., Cary, NC, USA), and associations were presented as odds ratio (OR) and 95\% confidence interval. For all tests, $P<0.05$ was considered significant.

\section{RESULTS}

\section{Study population}

The selection process of the study population is summarized in Figure 1. During the study period, 5,899 VLBW infants were born and registered in the KNN registry. After discharge, 2,759 (47.4\%) of the VLBW infants were followed up in outpatient clinics, and 1,053 VLBW infants (17.8\%) underwent the BSID test at corrected ages of 18 to 24 months. Of the 1,053 VLBW infants, 383 (36.3\%) underwent the BSID-III test. Of the 383 VLBW infants, 77 infants with abnormal findings in the neurological imaging tests $(n=43)$, IVH grade II or higher ( $\mathrm{n}=25)$, PVL $(\mathrm{n}=9)$, or major congenital malformation ( $n=8)$ were excluded. Eventually, 285 VLBW infants who underwent the BSID-III test at corrected ages of 18 to 24 months were included for analysis. The mean gestational age was 29 weeks (IQR, 27 to 30 weeks), and the mean birth weight was $1,130 \mathrm{~g}$ (IQR, 900 to 1,290 g) (Table 1). The mean gestational age and birth weight of the remaining group were 28.3 weeks $(P=0.06)$ and $1,074 \mathrm{~g}(P=0.17)$, respectively, which did not show statistical significance. Furthermore, three of the enrolled VLBW infants were diagnosed with $\mathrm{CP}$, and the mean discharge weight was $2,470 \mathrm{~g}$ (Table 2).

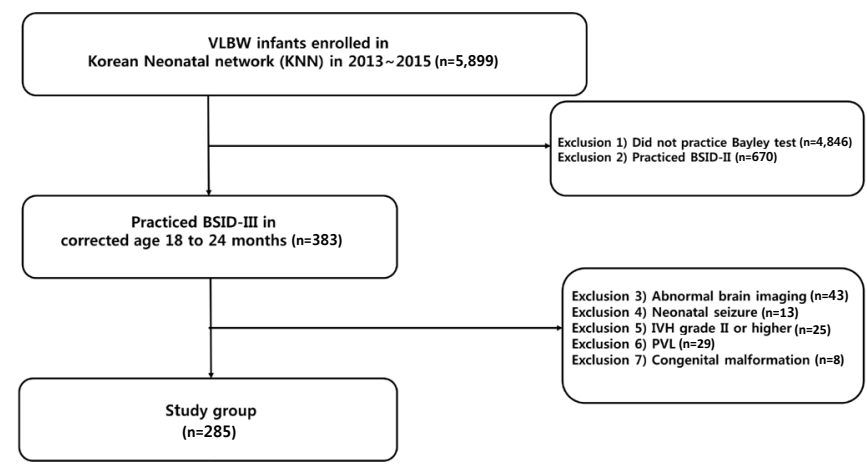

Figure 1. Enrollment of study group. Abbreviations: VLBW, verylow-birth-weight; BSID, Bayley Scales of Infant and Toddler Development; IVH, intraventricular hemorrhage; PVL, periventri cular leukomalacia. 
Table 1. Demographic Characteristics of the Enrolled Preterm Infants $(\mathrm{n}=285)$

\begin{tabular}{|c|c|}
\hline Variable & Value \\
\hline \multicolumn{2}{|l|}{ Neonatal characteristics } \\
\hline Singleton & $176(61.8)$ \\
\hline Male sex & $120(42.1)$ \\
\hline Gestational age (wk) & $29(27-30)$ \\
\hline Birth weight (g) & $1,130(900-1,290)$ \\
\hline Birth head circumference $(\mathrm{cm})(\mathrm{n}=279)$ & $26(24.5-27.5)$ \\
\hline IVF-ET & $76(26.6)$ \\
\hline Diabetes mellitus during pregnancy & $19(6.7)$ \\
\hline Hypertension during pregnancy & $70(24.6)$ \\
\hline Chorioamnionitis (n=263) & $99(37.6)$ \\
\hline Completion of antenatal corticosteroid $(\mathrm{n}=282)$ & $161(57.1)$ \\
\hline Cesarean delivery & $199(69.8)$ \\
\hline Resuscitation at birth & $241(84.6)$ \\
\hline 1-minute Apgar score $(\mathrm{n}=284)$ & $5(3-6)$ \\
\hline 5-minute Apgar score $(\mathrm{n}=284)$ & $7(6-8)$ \\
\hline \multicolumn{2}{|l|}{ Environmental characteristics } \\
\hline Maternal age (yr) & $33(31-35)$ \\
\hline \multicolumn{2}{|l|}{ Maternal educational level $(\mathrm{n}=261)$} \\
\hline$<$ College graduate & $51(19.5)$ \\
\hline$\geq$ College graduate & $210(80.5)$ \\
\hline \multicolumn{2}{|l|}{ Paternal educational level $(n=236)$} \\
\hline$<$ College graduate & $36(15.3)$ \\
\hline$\geq$ College graduate & $200(84.7)$ \\
\hline
\end{tabular}

Values are expressed as number (\%) or median (interquartile range). Abbreviation: IVF-ET, in vitro fertilization-embryo transfer.

\section{Neurodevelopmental assessment}

The incidence of developmental impairment was highest for language $(20.7 \%, 59 / 285)$, followed by cognition $(11.9 \%, 34 / 285)$ and motor function $(11.2 \%, 32 / 285)$. The mean \pm SD developmental scores in the cognition, language, and motor scales were 99.99 $\pm 13.59,95.14 \pm 14.72$, and $99.32 \pm 11.61$, respectively. The average score was the lowest in the language group in both total study and delayed VLBW groups. Moreover, the incidence of moderate and severe delay was the highest in the language scale (Table 3).

\section{Analysis for the predictors of adverse neurodevelopmental outcome}

In the univariate analysis, cognition delay was significantly associated with multiple factors. Lower 5-minute Apgar score, lower birth weight, moderate and severe BPD, IVH grade I, and longer TPN duration were associated with the poor cognitive outcome (Supplementary Table 1). However, in the multivariate
Table 2. Morbidities of the Enrolled Preterm Infants in Neonatal Intensive Care Unit $(\mathrm{n}=285)$

\begin{tabular}{lc}
\hline Variable & Value \\
\hline RDS & $199(69.8)$ \\
BPD (n=283) & $167(59.0)$ \\
$\quad$ BPD mild & $78(27.5)$ \\
$\quad$ BPD moderate & $49(17.3)$ \\
$\quad$ BPD severe & $40(14.1)$ \\
PDA ligation $(\mathrm{n}=284)$ & $30(10.6)$ \\
Hypotension & $50(17.5)$ \\
IVH grade I $(\mathrm{n}=284)$ & $63(22.2)$ \\
Culture proven sepsis & $51(17.9)$ \\
NEC stage $>2$ & $9(3.2)$ \\
ROP stage $\geq 3(\mathrm{n}=283)$ & $30(10.6)$ \\
Cerebral palsy $(\mathrm{n}=283)$ & $3(1.1)$ \\
Referred AABR $(\mathrm{n}=281)$ & $43(15.3)$ \\
Discharge weight $(\mathrm{g})(\mathrm{n}=270)$ & $2,470(2,210-2,930)$ \\
Discharge head circumference $(\mathrm{cm})(\mathrm{n}=278)$ & $32.4(31.1-33.5)$ \\
Total TPN duration $(\mathrm{d})$ & $16(10-28)$
\end{tabular}

Values are expressed as number (\%) or median (interquartile range). Abbreviations: RDS, respiratory distress syndrome; BPD, broncho pulmonary dysplasia; PDA, patent ductus arteriosus; IVH, intraven tricular hemorrhage; NEC, necrotizing enterocolitis; ROP, retinopathy of prematurity; AABR, automated auditory brainstem response; TPN, total parenteral nutrition.

Table 3. Overview of the Bayley Scales of Infant and Toddler Development Test Outcome of the Enrolled Infants at Corrected Ages of 18 to 24 Months $(n=285)$

\begin{tabular}{lccr}
\hline Variable & Cognition & Language & \multicolumn{1}{c}{ Motor } \\
\hline No delay & $251(88.1)$ & $226(79.3)$ & $253(88.8)$ \\
$\quad$ Mean \pm SD & $99.99 \pm 13.59$ & $95.14 \pm 14.72$ & $99.32 \pm 11.61$ \\
Delay & $34(11.9)$ & $59(20.7)$ & $32(11.2)$ \\
$\quad$ Mean \pm SD & $77.35 \pm 9.39$ & $73.68 \pm 8.39$ & $78.25 \pm 8.27$ \\
Moderate delay & $25(8.8)$ & $47(16.5)$ & $25(8.8)$ \\
Severe delay & $9(3.2)$ & $14(4.2)$ & $7(2.5)$
\end{tabular}

Values are expressed as number (\%).

Abbreviation: SD, standard deviation.

models, none of the factors were significantly related. IVH grade I $(P=0.079)$ and moderate and severe BPD $(P=0.056)$ were highly suspected predictors, and they showed marginal associations (Table 4).

In terms of the language delay, birth weight and head circumference at the time of birth and discharge were significant factors associated with the outcome in the univariate analysis (Supplementary Table 2). Also, IVH grade I and paternal educa tional level were associated with language delay. In the multi 
Table 4. Multivariate Analysis of the Cognitive Outcomes of Preterm Infants at Corrected Ages of 18 to 24 Months (n=285)

\begin{tabular}{|c|c|c|c|c|}
\hline \multirow{2}{*}{ Variable (cognition) } & \multicolumn{2}{|c|}{ Univariable } & \multicolumn{2}{|c|}{ Multivariable } \\
\hline & Odds ratio $(95 \% \mathrm{CI})$ & $P$-value & Odds ratio (95\% CI) & $P$-value \\
\hline 5-minute Apgar score & $0.80(0.67-0.94)$ & $<0.05$ & $0.83(0.66-1.05)$ & 0.124 \\
\hline Birth weight (g) & $0.99(0.99-1.00)$ & $<0.05$ & $1.00(0.99-1.00)$ & 0.883 \\
\hline Gestational age (wk) & $0.88(0.76-1.02)$ & 0.105 & $1.13(0.77-1.40)$ & 0.788 \\
\hline BPD moderate & $2.82(1.36-5.83)$ & $<0.05$ & $2.99(0.97-9.22)$ & 0.056 \\
\hline IVH grade I & $2.87(1.35-6.08)$ & $<0.05$ & $2.44(0.90-6.63)$ & 0.079 \\
\hline Total TPN duration (d) & $1.02(1.00-1.03)$ & $<0.05$ & $1.01(0.99-1.03)$ & 0.183 \\
\hline Higher maternal educational level $(n=261)$ & $0.72(0.30-1.72)$ & 0.467 & & \\
\hline Higher paternal educational level (n=236) & $0.49(0.18-1.34)$ & 0.168 & & \\
\hline
\end{tabular}

The multivariate analysis included parameters that showed association in the univariate analysis.

Abbreviations: CI, confidence interval; BPD, bronchopulmonary dysplasia; IVH, intraventricular hemorrhage; TPN, total parenteral nutrition.

Table 5. Multivariate Analysis of the Language Outcomes of Preterm Infants at Corrected Ages of 18 to 24 Months (n=285)

\begin{tabular}{|c|c|c|c|c|}
\hline \multirow{2}{*}{ Variable (language) } & \multicolumn{2}{|c|}{ Univariable } & \multicolumn{2}{|c|}{ Multivariable } \\
\hline & Odds ratio (95\% CI) & $P$-value & Odds ratio $(95 \% \mathrm{CI})$ & $P$-value \\
\hline Birth head circumference $(\mathrm{cm})$ & $0.86(0.76-0.98)$ & $<0.05$ & $0.93(0.72-1.21)$ & 0.634 \\
\hline Birth weight (g) & $0.99(0.99-1.00)$ & $<0.05$ & $0.99(0.99-1.00)$ & 0.104 \\
\hline Gestational age (wk) & $0.92(0.82-1.03)$ & 0.164 & $1.09(0.90-1.31)$ & 0.349 \\
\hline IVH grade I & $2.17(1.15-4.08)$ & $<0.05$ & $1.74(0.74-4.10)$ & 0.204 \\
\hline Head circumference at discharge $(\mathrm{cm})$ & $1.21(1.03-1.42)$ & $<0.05$ & $1.08(0.88-1.33)$ & 0.426 \\
\hline Higher maternal educational level $(\mathrm{n}=261)$ & $0.78(0.37-1.63)$ & 0.524 & & \\
\hline Higher paternal educational level $(n=236)$ & $0.37(0.17-0.81)$ & $<0.05$ & $0.33(0.14-0.77)$ & $<0.05$ \\
\hline
\end{tabular}

The multivariate analysis included parameters that showed association in the univariate analysis.

Abbreviations: $\mathrm{CI}$, confidence interval; IVH, intraventricular hemorrhage.

Table 6. Multivariate Analysis of the Motor Outcomes of Preterm Infants at Corrected Ages of 18 to 24 Months (n=285)

\begin{tabular}{|c|c|c|c|c|}
\hline \multirow{2}{*}{ Variable (language) } & \multicolumn{2}{|c|}{ Univariable } & \multicolumn{2}{|c|}{ Multivariable } \\
\hline & Odds ratio $(95 \% \mathrm{CI})$ & $P$-value & Odds ratio (95\% CI) & $P$-value \\
\hline 5-minute Apgar score & $0.82(0.69-0.97)$ & $<0.05$ & $0.90(0.65-1.24)$ & 0.901 \\
\hline Birth head circumference (cm) & $0.83(0.70-0.97)$ & $<0.05$ & $1.00(0.69-1.44)$ & 0.996 \\
\hline Birth weight (g) & $0.99(0.99-0.99)$ & $<0.05$ & $0.99(0.99-0.99)$ & $<0.05$ \\
\hline Gestational age (wk) & $0.90(0.78-1.05)$ & 0.202 & $1.28(0.89-1.83)$ & 0.172 \\
\hline BPD moderate & $2.81(1.33-5.94)$ & $<0.05$ & $2.84(0.52-15.43)$ & 0.226 \\
\hline IVH grade I & $2.76(1.27-5.97)$ & $<0.05$ & $2.10(0.56-7.84)$ & 0.269 \\
\hline Head circumference at discharge $(\mathrm{cm})$ & $1.35(1.10-1.65)$ & $<0.05$ & $1.71(1.17-2.50)$ & $<0.05$ \\
\hline Total TPN duration (d) & $1.02(1.00-1.03)$ & $<0.05$ & $0.99(0.97-1.02)$ & 0.843 \\
\hline
\end{tabular}

The multivariate analysis included parameters that showed association in the univariate analysis.

Abbreviations: CI, confidence interval; BPD, bronchopulmonary dysplasia; IVH, intraventricular hemorrhage; TPN, total parenteral nutrition.

variate analysis, the paternal educational level was the only related factor. As the paternal educational level increased, the incidence of language delay decreased (OR, 0.33; $P<0.05$ ) (Table 5).

In the univariate analysis of motor delay, birth weight, head circumference at birth, and 5-minute Apgar score were significant factors. Similar to other scales, moderate and severe BPD,
IVH grade I, total TPN duration, and head circumference at discharge were the major risk factors (Supplementary Table 3). In the multivariate analysis, birth weight and head circumference at discharge were significant factors associated with motor delay $(P<0.05)$ (Table 6). 


\section{DISCUSSION}

The study analyzed the current incidence of and significant risk factors associated with the poor neurodevelopmental outcome of VLBW infants at corrected ages of 18 to 24 months with BSID-III scores, especially those who did not show major brain injury. After discharge, $47.4 \%$ of the VLBW infants were followed up in outpatient clinics, and $17.8 \%$ underwent the BSID test at corrected ages of 18 to 24 months. The implementation rate of BSID in South Korea was lower than that of other nations, $79.1 \%$ in Switzerland and $74.9 \%$ in Canada ${ }^{6,18)}$. We insist that the implementation rate of the Bayley tests should be increased for proactive surveillance in VLBW infants.

In our study, $11 \%$ to $20 \%$ of VLBW infants showed poor neurodevelopmental outcome although the infants with neonatal brain injuries were excluded. Considering that the BSID-III test has a tendency to overestimate infants' neurodevelopmental status ${ }^{17,19)}$, the incidence of poor outcome would have been underestimated and may be higher.

Of the three categories in BSID-III, the incidence of language delay was the most prominent. Several studies showed that preterm infants without neurological impairment could have prominent language delay ${ }^{20)}$, which can persist through school age $^{21,22)}$. Therefore, early intervention is necessary, and there has been practical improvement in outcome ${ }^{23,24)}$. We emphasize the necessity of early intervention in language delay, even VLBW without evident brain injuries.

Our robust finding was that the paternal educational level was a significant factor associated with language delay in the multivariate analysis. Previous studies showed that socioeconomic status and maternal educational level were relevant environmental factors in developmental delay ${ }^{4,25,26)}$. However, to the best of our knowledge, this is the first study to emphasize the association of language delay with the paternal educational level in VLBW infants. Our study is in line with Pancsofar et al. ${ }^{27)}$ that the paternal educational level significantly contributed to the child's expressive language development. We could not determine whether the result affected the outcome directly or indirectly as our cohort had no data on the socioeconomic status, family stress factor, and home environment. However, we should emphasize that not only maternal factors but also paternal factors are crucial to language delay.

In our analysis, well known risk factors including ROP and NEC also did not impact the neurodevelopmental outcome in prematurity ${ }^{28-30)}$. On the contrary, birth weight and head circumference had significant effects on developmental delay, consistent with previous studies ${ }^{6}$. Among the predictable variables at discharge, BPD showed significant impacts on neurode velopmental outcome. Previous studies have shown that BPD could have an impact on the brain microstructure such as white matter connectivity and reduction in brain volume especially in the cerebellum and corpus callosum ${ }^{31,32)}$. Moreover, its chronic disease entity could adversely affect daily life and social interaction, which is a crucial factor for development. IVH grade I, which is controversial on its impact on delayed outcome, exhibited a marked influence ${ }^{33-35)}$. Similar to BPD, a previous study showed that IVH I affects the brain microstructure. It indicates that while VLBW have normal brain MRI findings, neonatal variables could actually impact on its microstructures.

A remarkable finding was that in the study group, three infants were diagnosed with diplegic CP. All of them did not show any signs of neurological abnormalities except IVH grade I. The result indicates that prematurity itself could be a crucial risk factor for CP. Also, it implies that clinicians should carefully observe the development of all VLBW infants, even those without brain injuries.

The strength of the study is that it is based on a large populationbased nationwide cohort. In our knowledge, this is the first study to analyze only VLBW infants without neurological abnormalities with BSID-III. Several limitations of this study need to be mentioned. Although our study is based on a nationwide cohort, the number of the study population was relatively small that we could not validate the prediction model. Also, as mentioned earlier, the implementation rate of the Bayley test was poor that it is unclear whether the result can represent the entire population. In the survey, environmental factors including socioeconomic status, residence, and children day care center were excluded, which could have affected the neurodevelopmental outcome.

In conclusion, approximately $20 \%$ of VLBW infants without major brain injury have developmental delay; language delay was the most prominent of the three categories. Factors that can assume developmental delay are BPD higher than moderate, IVH grade I, paternal educational level, birth weight, and head circumference at discharge. We emphasize that even in VLBW infants without brain injury, clinicians should be aware of the risk factors for poor neurodevelopmental outcome. 


\section{ARTICLE INFORMATION}

\section{Ethical statement}

The data registry was approved by the Institutional Review Board as each hospital was a participant in the Korean Neonatal Network (IRB No. 2013-06-025). Informed consent was obtained from all patients through their enrollment in NICUs participating in the Korean Neonatal Network.

\section{Supplementary materials}

Supplementary materials related to this article can be found online at https://doi.org/10.5385/nm.2020.27.4.151.

\section{Conflicts of interest}

No potential conflict of interest relevant to this article was reported.

\section{Author contributions}

Conception or design: J.H.C.

Acquisition, analysis, or interpretation of data: J.H.C., N.C., Y.J.K.

Drafting the work or revising: J.H.C., H.J.L., C.R.K., H.K.P.

Final approval of the manuscript: H.K.P.

\section{ORCID}

Jong Ho Cha https://orcid.org/0000-0002-7883-8714

Hyun-Kyung Park https://orcid.org/0000-0001-5956-9208

\section{Acknowledgments}

This research was supported by a fund (2019-ER7103-00\#) by Research of Korea Centers for Disease Control and Prevention.

\section{REFERENCES}

1. Hahn WH, Chang JY, Chang YS, Shim KS, Bae CW. Recent trends in neonatal mortality in very low birth weight Korean infants: in comparison with Japan and the USA. J Korean Med Sci 2011; 26:467-73.

2. Ahn SH, Kim SA. Assessment of preterm infants using the Bayley-III scales in Korea. Ann Rehabil Med 2017;41:843-50.

3. Potharst ES, van Wassenaer AG, Houtzager BA, van Hus JW, Last $\mathrm{BF}, \mathrm{Kok} \mathrm{JH}$. High incidence of multi-domain disabilities in very preterm children at five years of age. J Pediatr 2011;159:79-85.

4. Guerra CC, Barros MC, Goulart AL, Fernandes LV, Kopelman BI,
Santos AM. Premature infants with birth weights of 1500-1999 g exhibit considerable delays in several developmental areas. Acta Paediatr 2014;103:e1-6.

5. Kerstjens JM, Bocca-Tjeertes IF, de Winter AF, Reijneveld SA, Bos AF. Neonatal morbidities and developmental delay in moderately preterm-born children. Pediatrics 2012;130:e26572.

6. Schlapbach LJ, Adams M, Proietti E, Aebischer M, Grunt S, Borradori-Tolsa C, et al. Outcome at two years of age in a Swiss national cohort of extremely preterm infants born between 2000 and 2008. BMC Pediatr 2012;12:198.

7. Ambalavanan N, Baibergenova A, Carlo WA, Saigal S, Schmidt B, Thorpe KE, et al. Early prediction of poor outcome in extremely low birth weight infants by classification tree analysis. J Pediatr 2006;148:438-44.

8. Woodward LJ, Anderson PJ, Austin NC, Howard K, Inder TE. Neonatal MRI to predict neurodevelopmental outcomes in preterm infants. N Engl J Med 2006;355:685-94.

9. Woodward LJ, Clark CA, Bora S, Inder TE. Neonatal white matter abnormalities an important predictor of neurocognitive outcome for very preterm children. PLoS One 2012;7:e51879.

10. Sharp M, DeMauro SB. Counterbalanced comparison of the BSID-II and Bayley-III at eighteen to twenty-two months corrected age. J Dev Behav Pediatr 2017;38:322-9.

11. Jung YH, Park Y, Kim BI, Choi CW. Length at birth z-score is inversely associated with an increased risk of bronchopulmonary dysplasia or death in preterm infants born before 32 gestational weeks: a nationwide cohort study. PLoS One 2019; 14:e0217739.

12. Chang YS, Park HY, Park WS. The Korean Neonatal Network: an overview. J Korean Med Sci 2015;30 Suppl 1(Suppl 1):S3-11.

13. Jobe AH, Bancalari E. Bronchopulmonary dysplasia. Am J Respir Crit Care Med 2001;163:1723-9.

14. Bell MJ, Ternberg JL, Feigin RD, Keating JP, Marshall R, Barton L, et al. Neonatal necrotizing enterocolitis: therapeutic decisions based upon clinical staging. Ann Surg 1978;187:1-7.

15. Papile LA, Burstein J, Burstein R, Koffler H. Incidence and evolution of subependymal and intraventricular hemorrhage: a study of infants with birth weights less than 1,500 gm. J Pediatr 1978;92:529-34.

16. Rosenbaum P, Paneth N, Leviton A, Goldstein M, Bax M, Damiano D, et al. A report: the definition and classification of cerebral palsy April 2006. Dev Med Child Neurol Suppl 2007; 109:8-14.

17. Johnson S, Moore T, Marlow N. Using the Bayley-III to assess neurodevelopmental delay: which cut-off should be used? Pediatr Res 2014;75:670-4.

18. Asztalos EV, Church PT, Riley P, Fajardo C, Shah PS; Canadian Neonatal Network and Canadian Neonatal Follow-up Network Investigators. Neonatal factors associated with a good neurode- 
velopmental outcome in very preterm infants. Am J Perinatol 2017;34:388-96.

19. Anderson PJ, de Luca CR, Hutchinson E, Roberts G, Doyle LW; Victorian Infant Collaborative Group. Underestimation of developmental delay by the new Bayley-III Scale. Arch Pediatr Adolesc Med 2010;164:352-6.

20. Sansavini A, Guarini A, Justice LM, Savini S, Broccoli S, Alessandroni R, et al. Does preterm birth increase a child's risk for language impairment? Early Hum Dev 2010;86:765-72.

21. Barre N, Morgan A, Doyle LW, Anderson PJ. Language abilities in children who were very preterm and/or very low birth weight: a meta-analysis. J Pediatr 2011;158:766-74.

22. Van Noort-van der Spek IL, Franken MC, Weisglas-Kuperus N. Language functions in preterm-born children: a systematic review and meta-analysis. Pediatrics 2012;129:745-54.

23. Milgrom J, Newnham C, Martin PR, Anderson PJ, Doyle LW, Hunt RW, et al. Early communication in preterm infants follow. ing intervention in the NICU. Early Hum Dev 2013;89:755-62.

24. Hintz SR, Kendrick DE, Vohr BR, Poole WK, Higgins RD; National Institute of Child Health and Human Development (NICHD) Neonatal Research Network. Community supports after surviving extremely low-birth-weight, extremely preterm birth: special outpatient services in early childhood. Arch Pediatr Adolesc Med 2008;162:748-55.

25. Wang LW, Wang ST, Huang CC. Preterm infants of educated mothers have better outcome. Acta Paediatr 2008;97:568-73.

26. Luu TM, Vohr BR, Schneider KC, Katz KH, Tucker R, Allan WC, et al. Trajectories of receptive language development from 3 to 12 years of age for very preterm children. Pediatrics 2009;124:33341.

27. Pancsofar N, Vernon-Feagans L. Mother and father language input to young children: contributions to later language de- velopment. J Appl Dev Psychol 2006;27:571-87.

28. Schmidt B, Asztalos EV, Roberts RS, Robertson CM, Sauve RS, Whitfield MF, et al. Impact of bronchopulmonary dysplasia, brain injury, and severe retinopathy on the outcome of extremely low-birth-weight infants at 18 months: results from the trial of indomethacin prophylaxis in preterms. JAMA 2003;289:1124-9.

29. Bassler D, Stoll BJ, Schmidt B, Asztalos EV, Roberts RS, Robertson $\mathrm{CM}$, et al. Using a count of neonatal morbidities to predict poor outcome in extremely low birth weight infants: added role of neonatal infection. Pediatrics 2009;123:313-8.

30. Stoll BJ, Hansen NI, Adams-Chapman I, Fanaroff AA, Hintz SR, Vohr B, et al. Neurodevelopmental and growth impairment among extremely low-birth-weight infants with neonatal infection. JAMA 2004;292:2357-65.

31. Lee JM, Choi YH, Hong J, Kim NY, Kim EB, Lim JS, et al. Bronchopulmonary dysplasia is associated with altered brain volumes and white matter microstructure in preterm infants. Neonatology 2019;116:163-70.

32. Shim SY, Jeong HJ, Son DW, Jeong JS, Oh SH, Park SY, et al. Altered microstructure of white matter except the corpus callosum is independent of prematurity. Neonatology 2012;102: 309-15.

33. Reubsaet P, Brouwer AJ, van Haastert IC, Brouwer MJ, Koopman C, Groenendaal F, et al. The impact of low-grade germinal matrix-intraventricular hemorrhage on neurodevelopmental outcome of very preterm infants. Neonatology 2017;112:203-10.

34. Klebermass-Schrehof K, Czaba C, Olischar M, Fuiko R, Waldhoer T, Rona Z, et al. Impact of low-grade intraventricular hemorrhage on long-term neurodevelopmental outcome in preterm infants. Childs Nerv Syst 2012;28:2085-92.

35. Fearon P, O'Connell P, Frangou S, Aquino P, Nosarti C, Allin M, et al. Brain volumes in adult survivors of very low birth weight: a sibling-controlled study. Pediatrics 2004;114:367-71. 